\title{
Hong Kong 2020. Taking the Pulse
}

\author{
香港2020脈搏 \\ Ivy Fung ${ }^{1}$, HoiLam Tang ${ }^{2}$, NgaChee Chan, Tristan ${ }^{3}$ \\ ${ }^{1}$ HKAAT, Hong Kong, China \\ ${ }^{2}$ ATR-BC, Hong Kong, China \\ ${ }^{3}$ BAAT, Hongkong, China
}

\begin{abstract}
Three veteran art therapists reflect on thedevelopment of the art therapy professionin Hong Kong over the past 10 years, the ways in which it has changed and the struggles still in front of them. From qualifying outside of Hong Kong, to the establishment of the Hong Kong Associationof Art Therapy (HKAAT), to adapting the models to Hong Kong society and Chinese culture, to the current pandemic (COVID 19), the art therapists share a love for art and a devotion to the field.
\end{abstract}

Keywords: Art therapy, Hong Kong, professional development, professional accreditation, health care

\section{摘要}

三位資深藝術治療師反思了香港藝術治療專業在過去十年中的發展，其變化方式以及仍 然面臨的挑戰。從來自香港以外的認可，到成立香港藝術療法協會（HKAAT），使模 型適應香港社會和中國文化，再到當前的流行病（COVID 19），藝術治療師充滿對藝 術和對領域的熱愛。

关键词：藝術療法，香港，專業發展，專業認證，醫療保健

Three veteran art therapists Ivy Fung, HoiLam Tang, and Tristan Chan reflect on the development of art therapy over the past 10 years. These three art therapists recall being lone professionals representing an unknown an unrecognized profession. Art therapy is differentiated here from Expressive Arts therapy, which came to Hong Kong some years later (see Kalmanowitz, Introduction, Hong Kong 2020: Expressive arts therapy in Hong Kong. Yesterday and Today)

\section{Ivy Fung}

It has been almost 30 years since art therapy first arrived in Hong Kong. Since then, the profession has grown in scope and intensity. During the first decade, art therapy work was mainly incorporated into the therapists' jobs as an affiliate. For instance, a teacher would run art therapy groups in a school, or a bereavement counsellor would use art therapy in the palliative care unit. It was not until the millennium that nongovernmental organizations (NGOs) began to employ part-time and, very rarely, full-time art therapists. The establishment of the Hong Kong Association of Art Therapists in 2002, planted a seed in the mind of the public and art therapy began to 
be recognized as a profession in its own right. More institutions and organizations set up art therapist posts, art therapy workshops and groups began to be in high demand.

After that seedling stage, we had a clearer picture as to how far and how deep the profession had grown. In 2010, there were organizations which expanded their services specifically to include art therapy. Baptist Oi Kwan Social Service, provides integrated mental health service and opened an arts therapy center which is still expanding, some schools began to employ full-time or part-time art therapists to take care of the intensive needs of Hong Kong students. Many other institutes began to include art therapy as a regular service. Since 2004, resource centers for cancer patients at the Prince of Wales Hospital and the Princess Margaret Hospital have invited art therapists to run groups for clients with different needs in their treatment and recovery and today hundreds of clients have benefited from art therapy.

Towards the second half of 2010 as the Hong Kong Art Therapy Association (HKAAT) matured, there were further reforms, and the association adapted a more proactive approach in educating society. International art therapy conferences introduced Hong Kong's caring professionals to experts from around the world. Caring professionals who believe in the healing power of art, had a platform from which to learn about the possibility of incorporating art therapy into their settings.

During the recent social unrest, HKAAT quickly responded to the desperate emotional needs of the people of Hong Kong, by forming art therapy relief groups in different languages to cater to the multi-cultural population in Hong Kong. It also encouraged fellow members to post their own artwork on social media, so that people know how art can be used to heal. I find the association's social alertness a good reminder to all art therapists practicing in Hong Kong of our own social responsibilities.

This new decade of 2020 has provided many challenges both locally and globally. We see a greater demand in mental health services with limited resources on the individual and institutional level. Some of the questions we now face are: how do we create more channels to let the public benefit from art therapy? How do we best go about attaining professional accreditation in the government health system? How do we as art therapists/artists continue to learn from art and from our lives? We have come a long way and there is still a long way to go.

\section{HoiLam Tang}

Hong Kong qualified art therapists have at least doubled since 2012 when there were less than 20 professional members based on HKAAT's data. In 2020, approximately 40 qualified art therapists are practicing in Hong Kong and over 30 of them have joined the HKAAT professional membership.

Art therapy has expanded from being a middle-class service, available primarily in private settings through private practice, to including working with non-government organizations serving cancer patients, children and teens who have suffered from trauma, and adults with severe mental health issues. More recently art therapy has further diversified, with art therapy programs to be found in work with special 
education, children on autism spectrum, the elderly, and severely mentally and physical disable adults. In addition, art therapy is in a handful of schools, it is included as part of a secondary school counseling team and community art programs. Art therapists are now being employed not only for illness but also as an integral part of well-being services.

A further advance is a move away from traditional clinical settings and social services teams to art therapists participating in a community-development forums and an engagement with the general public on the benefit of art and how art therapy might work in non-clinical ways. Despite these advances, the majority of art therapists in Hong Kong are self-employed in private practice or are working freelance while only a few have part-time or full-time employment.

At this point there is no local regulation nor registration system for the art therapy profession. This means that there is no code of ethics or regulation of the profession, which could lead to problems in the future. In addition, without legal regulation, much work is being carried out under the name of "art therapy", projects, programs, services, or courses in the community are available yet they might not necessary be provided by a qualified art therapist. The lack of regulation continues to put the general public at risk, especially for those who are in need of professional clinical care or are in a vulnerable mental state.

Misunderstanding and misconception of art therapy remain a concern in the art therapy community. The idea that art therapy equals projective drawing remains one of the core beliefs among the general public and in recent years, coloring books and certain franchised art techniques have been added to this list. As a result of the former, some art therapists are taking an active role in providing public education in various settings and are regularly providing in-service workshops in their workplaces. There has been a significant growth of newspaper interviews, community forum sharing, book publications, articles written in printed and social media, and research publications in professional journals in recent years where the general public can acquire more accurate information about art therapy so that they can make appropriate decisions when it comes to seeking a therapy service. Without regulation, however, there are still going to be non-art therapy trained art therapy services in the community.

Hong Kong is well known for its high level of stress from work and school. Once it was also known as one of the safest places in the world. With the recent social issues since June 2019, the level of stress, fear, anxiety, hatred, and mistrust have risen exponentially and a general sense of loss of safety has become the norm. In response to the social issues, art therapists have volunteered to provide community support services for those affected by the social events (through their place of work [social services, school, NGOs], some under the umbrella of HKAAT, while others are in private practice). Many young people have felt a high level of stress and anxiety, with a loss of trust in the adults in their lives. While trust was difficult to establish, art therapy groups became a useful form of therapy for participants as art expression provided a forum which demanded fewer words, while at the same time allowed for exposure to the artwork of group members. Through these groups compassion and empathy has been acknowledged and feelings of universality allowed to surface. 
With the arrival of the coronavirus in early 2020, social interactions have come to a halt and in addition, traditional forms of support have come to a standstill. In order to comply with the medical guidelines, social distancing has prevented many clients from receiving direct therapy service. Art therapists are slowly developing safety policies and suitable and confidential ways to conduct tele-therapy.

After nearly 10 months of back and forth between traditional forms of art therapy to online formats, art therapists begin to reflect and share how this change might be helpful yet challenging in practice.

From a positive perspective, for those facing physical challenges, medical issues, or living in remote areas, the options of online groups and individual sessions has increased accessibility of services. For participants who are in a high level of anxiety, online sessions have provided a safe space and allowed them to feel more secure and in control.

The practice of art as therapy has been fully embraced by many. In order to participate in art therapy online, many have had to set up an artmaking space in our homes. This practice has flourished and led to creativity among participants. The continuation of art therapy session has extended after the time of the session. In normal working practice, participants have to wrap up and leave the art room once the scheduled time is over, but for an online art therapy session, participants can take a pause when therapist asks for reflection or sharing, but once it is over and after all the goodbyes, the participants can continue to engage in their art making and further self-reflection.

As COVID-19 does not seem to be subsiding, many art therapists are beginning to embrace social media to promote and demonstrate stay-at-home artmaking ideas as well as promoting psychological well-being. The dimensions of art therapy have expanded from the clinical room to a public platform rapidly in this COVID-19 period.

Privacy issues have become a big concern however, especially for Hong Kong people who are live in small spaces. Some clients choose to stay in their car for online sessions as this is the only space they have with some privacy. While online session and groups allow emotional connection and expression, the aspect of social and physical connection cannot be fully fulfilled. Speech can be delayed by a few seconds and become a discouragement for further verbal engagement. The creative process cannot fully be witnessed as participants are not sharing the same space and this decreases their chance of mutual understanding and support.

With a rising sense of chaos and months of social distancing, art therapists have retreated back to their own creative processes to deal with their own personal needs. Many are actively making art to vent their feelings and organize their thoughts. Several art therapists have had exhibitions to raise public awareness and promote self-care via art making.

\section{NgaChee Chan, Tristan}

I can recall my first newspaper interview about art therapy back in 2012. The reporter was very interested in art therapy but could only find information from outside of Hong 
Kong and only in English. There were many clarifications needed and many stereotypes and misunderstandings to explain during the interview. Beginning then, until today, 2020, I find that I am being approached by multiple local journalists who have been inspired by and are inquisitive about the profession and are interested in writing about our work. Their awareness and understanding of art therapy have been surprising and fast-growing. From only a stereotypical approach, to beginning to understand that it is a form of psychotherapy, from thinking it is only applicable to children, to understanding it is for all ages. I have been interviewed about art therapy in the community, schools, health care, and private settings. The profession is growing at a fast pace in terms of public awareness and understanding.

That growth is also happening in the job market. Increasingly stakeholders who become involved in developing art therapy are thinking more systematically about how their projects can benefit from the involvement of art therapists. This is reflected in terms of the length and scale of the projects.

Mutual understanding between organizations and art therapists seems to be becoming increasingly common and the need for art therapists is also reflected by the growing number of long-term positions available. The opportunity for professional growth has flourished with a new awareness of the importance of evidence-based practice and research, a new interest in publishing and learning from each other and the world. The World Health Organization has summarized about 900 journal articles about the effectiveness of using arts in supporting well-being in 2019 (Fancourt \& Finn, 2019). In the past 8 years in Hong Kong, there have been two art therapy conferences organized by, and more than ten creative arts therapy conferences (including music, drama, dance and movement, and the expressive arts), as a result of collaborations between local therapists' associations, NGOs, or teaching institutes. Practitioners are working hard to develop evidence-based practice and learning to bridge our creative sense with academic presentation.

In response to the social unrest and the pandemic of COVID-19, art and art therapy has been used significantly during these difficult times. From online art tours of worldfamous museums and galleries, online art games and activities, to online art therapy, art has been used as a means to contain anxiety during these unsettled times. During this house-bound period, many organizations such as United Nations Children's Fund (UNICEF), Art in Hospital (HK), HKAAT (HK), have suggested and created some structured art activities or have proposed using art as a reflective practice for the general public to maintain our mental health and well-being. Reflective practices are considered an integral and cumulative form of learning in creative disciplines (Ryan, 2014). Art therapists, clients, and every person in the world have had to adjust to the change; new policies, norms, and expectations. Despite the challenges and risks, there are many opportunities to using online art therapy, but much is still unknown. My hope is that we can do more than adapt to these current challenges, we can also grow and learn. 


\section{About the Authors}

Ivy Fung has been working as an art therapist in Hong Kong for over 20 years. She has endeavored to develop art therapy as her personal career as well as being a recognized mental health profession in the city. She has worked with various groups of people and was a co-founder of the HKAAT.

HoiLam Tang is a board certified art therapist (ATR-BC). She provides art therapy services to a wide range of populations in Hong Kong and actively engages in raising community awareness on mental health issues.

NgaChee Chan, Tristan qualified and registered as an art psychotherapist in 2009 in the UK. She is a recognized clinical supervisor and a full member of BAAT, and the former vice president and a professional member of HKAAT. She published a book in Chinese titled: Embracing Imperfection: Wild Art Therapist in 2016, Joint Publishing (H.K.) Co., Ltd. Hong Kong.

\section{References}

Fancourt, D., \& Finn, S. (2019). What is the evidence on the role of the arts in improving health and wellbeing? A scoping review. Copenhagen: WHO Regional Office for Europe; (Health Evidence Network [HEN] synthesis report 67).

Ryan, M. E. (2014). Reflective practice in the arts. In: Barton G. (eds) Literacy in the Arts. Springer, Cham. https://doi.org/10.1007/978-3-319-04846-8_5 